\title{
Verrucous Bowen's Disease of the Plantar Foot
}

\author{
ROY C. GREKIN, M.D.
}

NEIL A. SWANSON, M.D.

Abstract. A patient is presented with a recurrent plantar tumor present for 15 years. This hyperkeratotic exophytic tumor behaved historically and appeared clinically to be a verrucous carcinoma. Biopsy revealed Bowen's disease. The tumor was successfully treated with Mohs surgery. The tumor is presented due to its unusual location and its appearance that closely resembled verrucous carcinoma. The Mohs technique allows for total tumor ablation with maximal preservation of tissue in this important functional area.

Verrucous carcinoma (VC) of the plantar foot is an uncommon or rare tumor not described in the literature until $1954 .^{1}$ It is characterized clinically by its indolent nature and morphologic similarity to plantar warts. ${ }^{2}$ Histologically, it is deceptively benign in appearance. ${ }^{3}$ However, it is considered by some to be a subset of cutaneous squamous-cell carcinoma. ${ }^{4}$ Capable of aggressive local invasion, the tumor rarely metastasizes unless irradiated..$^{5}$ Bowen's disease (BD), a variant of squamous-cell carcinoma, is a much more common entity than verrucous carcinoma ( $\mathrm{VC}$ ). Its occurrence on the plantar foot, however, is rare. ${ }^{6}$ Histologically this tumor is distinct from VC, displaying a disorderly, highly pleiomorphic picture involving full-thickness epidermis. ${ }^{7}$ Clinically, BD is less indurated, less keratotic, and not exophytic when compared with $\mathrm{VC}^{7}$ More importantly, once it penetrates the basement

Roy C. Grekin, M.D., Assistant Professor, and Neil A. Swanson, M.D., Assistant Professor, are with the Department of Dermatology, University of Michigan Medical School, Ann Arbor, Michigan.

Address reprint requests to Roy C. Grekin, M.D., University of Michigan, Department of Dermatology, C2065 Outpatient Building, Ann Arbor, MI 48109. membrane, invasive $\mathrm{BD}$, in sharp contrast to $\mathrm{VC}$, demonstrates a higher propensity toward regional metastasis. ${ }^{8}$

A case is reported in which a tumor of the plantar skin behaved historically and appeared clinically as a VC but following removal and microscopic examination was histologically determined to be BD. The lesion was successfully treated by Mohs surgery.

\section{CASE REPORT}

A 68-year-old woman in otherwise good health was referred to the Mohs Surgery Unit at the University of Michigan for treatment of a suspected VC. This lesion, located on the central right plantar foot, was originally examined 15 years earlier. At that time a diagnosis of plantar wart was made based on clinical appearance. The lesion was treated with liquid nitrogen with apparent resolution. The lesion recurred approximately 3 years later and slowly progressed until the time of presentation. The patient was able to continue work and was pain free despite having a central plantar tumor measuring $2.8 \times 2.0 \mathrm{~cm}$ that was extremely keratotic and exophytic (Fig. 1). The lesion was well demarcated and demonstrated a surrounding "moat," which is characteristic of VC. There was no inguinal adenopathy. Because of the clinical history and appearance, strongly suggestive of $\mathrm{VC}$, she was referred to the Mohs Surgery Unit for microscopically controlled excision of the lesion. After obtaining a biopsy and debulking the tumor, a tumor-free plane was achieved with a one-stage, six-section procedure resulting in a $3.0 \times 3.4 \mathrm{~cm}$ defect (Fig. 2). This 


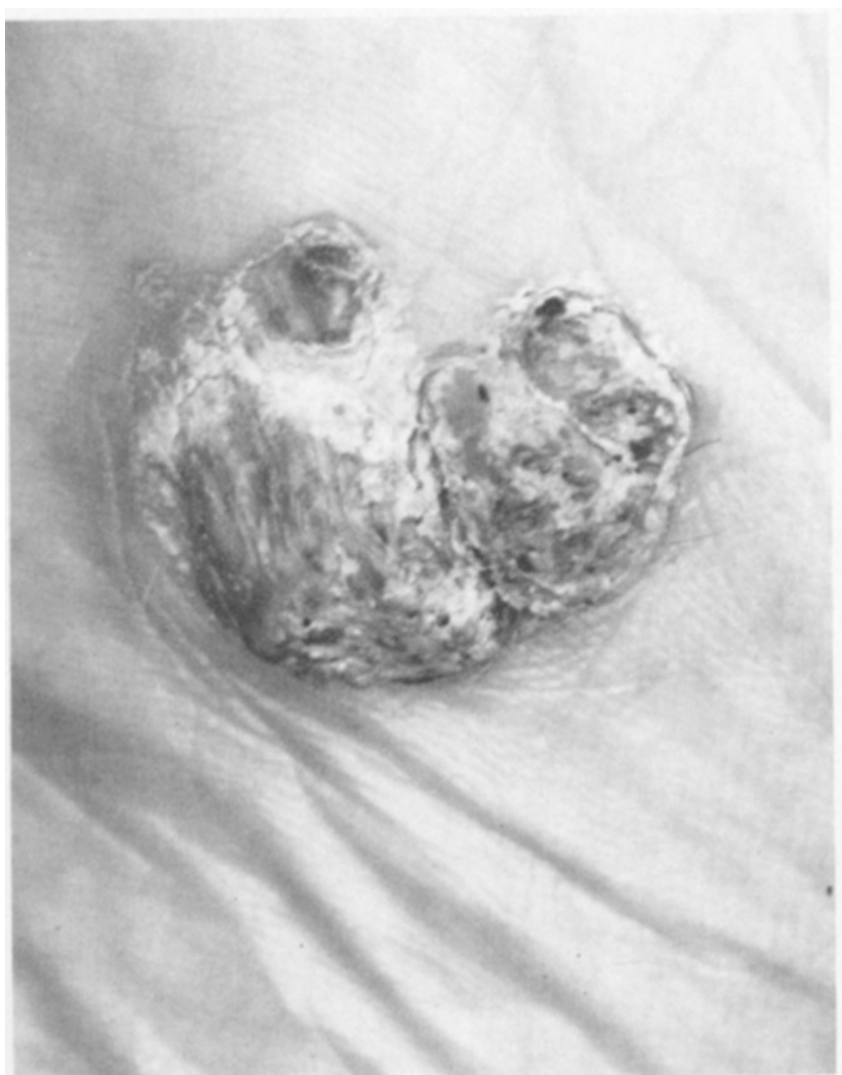

FIGURE 1. Pretreatment lesion, plantar skin right foot.

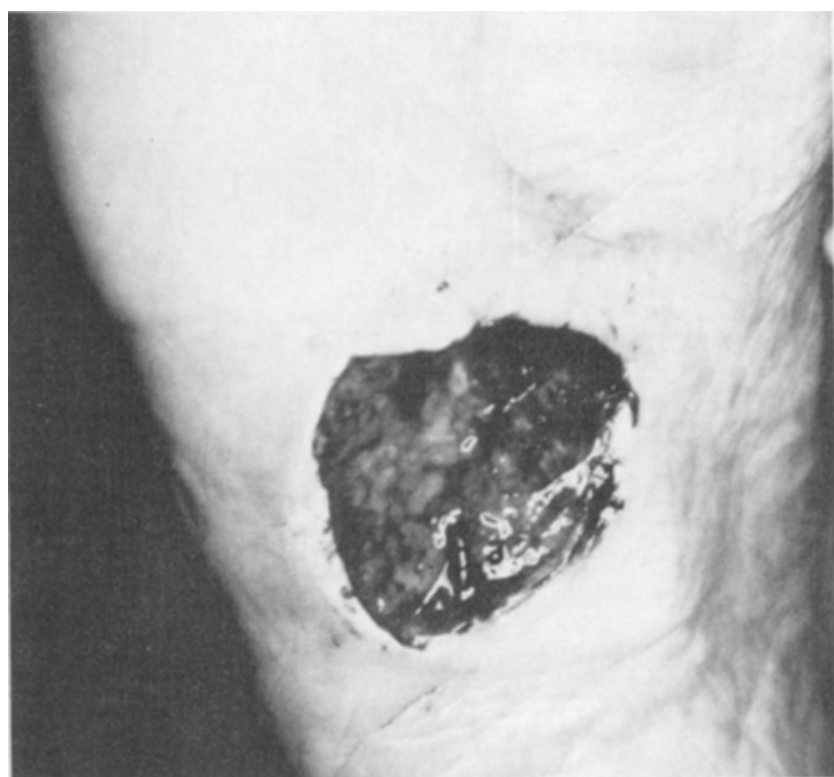

FIGURE 2. Postoperative defect following Mohs surgery.

was allowed to heal by secondary intention with complete re-epithelialization in 10 weeks (Fig. 3). She has remained free of recurrence locally with no evidence of metastasis for 18 months. History and physical examination have not been suggestive of internal malignancy.

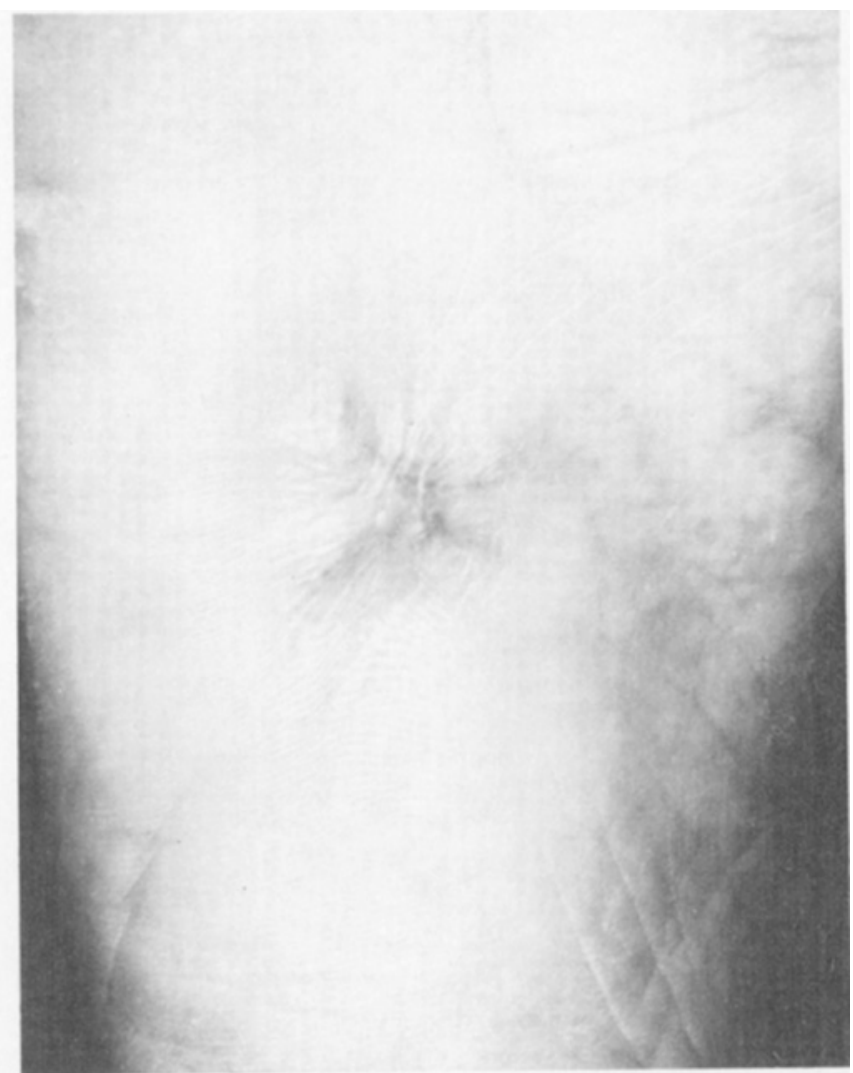

FIGURE 3. Healing by secondary intention complete 10 weeks after surgery.

\section{HISTOLOGY}

Microscopically, the lesion was verruciform with thick ortho- and parakeratotic hyperkeratosis overlying an acanthotic epidermis with papillomatosis. There was extensive squamous intraepidermal atypia involving the full thickness of the epidermis (Fig. 4). Numerous mitotic figures, including abnormal mitotic figures and multiple mitoses within the same cell, were present at all levels. Individually dyskeratotic cells were scattered throughout the disorderly stratum malpighii. There was no sign of invasion across the basement membrane. The histologic diagnosis by three pathologists was squamous-cell carcinoma, Bowen's type (Bowen's disease).

\section{COMMENTS}

We present this case because it represents BD occurring in an unsuspected location and also because the clinical history and appearance were strongly suggestive of a diagnosis of VC.

Bowen's disease, although it is more common than $\mathrm{VC}$, is rare on the plantar skin. In the Graham and 


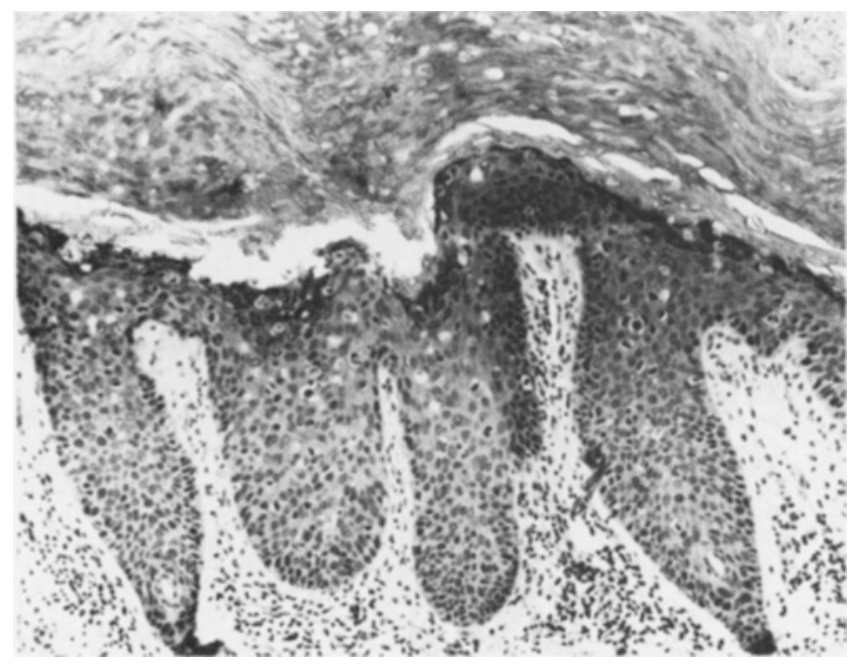

FIGURE 4. Histologic appearance of the patient's tumor. Note thick hyperkeratosis and canthosis. Multiple dyskeratotic cells and numerous mitoses are spread throughout the epidermis.

Helwig ${ }^{6}$ series of 155 patients with 211 tumors, none occurred on the soles of the feet. Similar to VC, BD has been described on mucous membranes and genitalia. ${ }^{6}$ However, unlike $\mathrm{VC}, \mathrm{BD}$ can occur anywhere, with one-third of all lesions occurring on the head. ${ }^{6}$ Clinically, BD is described as an erythematous sharply marginated firm plaque. It has scale but is not described as being thickly hyperkeratotic as is plantar VC. ${ }^{7}$ In our case the constant trauma of walking on the lesion may possibly have stimulated the hyperkeratosis. Microscopically the two tumors are quite distinct. VC exhibits a benign cytologic appearance with bulbous dermal expansion of the rete ridges. ${ }^{3} \mathrm{BD}$ shows full-thickness epidermal cellular atypia with multiple and bizarre mitoses at all levels. ${ }^{7}$ Although both are capable of local invasion, $\mathrm{BD}$, once through the basement membrane and invasive, is more likely to metastasize to regional lymph nodes than $V C^{8}$

We believe our decision to employ Mohs surgery to treat this lesion is well grounded. In our clinic, it is routine practice to treat recurrent tumors with this technique. However, other techniques could be considered. Cryosurgery was utilized in the initial treatment 15 years earlier and was not successful. Moreover, the extremely keratotic, exophytic na- ture of this tumor, as well as its large size, would mitigate against cryosurgery successfully treating the recurrence. Scalpel excision without microscopic control could result in either recurrence if too narrow a margin is taken or unnecessary loss of important functional tissue if too wide a margin is excised. Curettage and electrodesiccation likewise afford no control of tumor margins and may result in a debilitating scar. A case of plantar BD was presented by Allen et $\mathrm{al}^{9}$ in which cryosurgery was initially employed. The tumor recurred and was subsequently treated by wide local excision and grafting. We believe that, by using the Mohs technique, maximal plantar tissue can be preserved. More importantly, the entire undersurface and margins of the tumor can be examined for invasion through the basement membrane. If none is found, the patient can be assured with a high degree of confidence of an excellent prognosis. Should invasion be encountered, the physician is alerted to the necessity of close clinical follow-up and the possibility of recommending regional node dissection if nodes become clinically apparent.

\section{REFERENCES}

1. Aird, I., Johnson, H. D., Lennox, B., and Stansfeld, A. G. Epithelioma cunniculatum: A variety of squamous cell carcinoma peculiar to the foot. Br. J. Surg. 42:245-250, 1954.

2. Brownstein, M. H., and Shapiro, L. Vorrucous carcinoma of skin: Epithelioma cunniculatum plantare. Cancer 38:1710-1716, 1976.

3. Lever, W. F., and Schaumberg-Lever, G. Histopathology of the Skin, 6th ed., Philadelphia, Lippincott, 1983, p. 505.

4. Headington, J. T. Verrucous carcinoma. Cutis 21:207-211, 1978.

5. Perez, C. A., Kraus, F. T., Evans, J. C., and Powers, W. E. Anaplastic transformation in verrucous epidermal carcinoma of the oral cavity following irradiation. Cancer 26:389-393, 1970.

6. Graham, J. H., and Helwig, E. B. Bowen's disease and its relationship to systemic cancer. Arch. Dermatol. 83:738-758, 1961.

7. Lever, W. F., and Schaumberg-Lever, G. Histopathology of the Skin, 6th ed., Philadelphia, Lippincott, 1975, pp. 496-498.

8. Knox, J. M., and Joseph, L. M. Bowen's disease and erythroplasia: In Andrade, R., Gumport, S. L., Popkin, G. L., and Rees, T. D. (eds.), Cancer of the Skin. Philadelphia, Saunders, 1976, pp. 645-656.

9. Allen, R. B., Richardson, D. R., and Futrell, J. W. Bowen's disease of the plantar arch. Cutis 23:805-807, 1979. 